\title{
Normative Social Influence is Underdetected
}

\author{
Jessica M. Nolan \\ University of Arkansas \\ P. Wesley Schultz \\ California State University, San Marcos \\ Robert B. Cialdini \\ Arizona State University \\ Noah J. Goldstein \\ University of Chicago \\ Vladas Griskevicius \\ University of Minnesota
}

The present research investigated the persuasive impact and detectability of normative social influence. The first study surveyed 810 Californians about energy conservation and found that descriptive normative beliefs were more predictive of behavior than were other relevant beliefs, even though respondents rated such norms as least important in their conservation decisions. Study 2, a field experiment, showed that normative social influence produced the greatest change in behavior com- pared to information highlighting other reasons to conserve, even though respondents rated the normative social influence produced the greatest change in behavior compared to information highlighting other reasons to conserve, even though respondents rated the normative information as least motivating. Results show that normative messages can be a powerful lever of persuasion but that their influence is underdetected.

Keywords: social norms; social influence; pro-environmental behavior; social inference

Authors' Note: Funding for this study was provided by a grant from the Hewlett Foundation (20017396) and by National Science Foundation Graduate Research Fellowships provided to the fourth and fifth authors. Our appreciation goes to Kimberly Brown, Allen Risley, and Lori Large from the Social and Behavioral Research Institute and Azar Khazian for their help on Study 1. We also want to acknowledge the work of our field research team on Study 2: Veronica Briseno, Dulcinea Contreras, Matt Dorlaque, Reginald Hartfield, Edgar Medina, Laura Murphy, Leezel Nazareno, Rene Quiroz, Ronald Tilos, Monica Tinajero, and Christina Wade. Study 2 was conducted while the first author was at California State University, San Marcos, as part of her master's thesis. Portions of this article were presented at the annual meeting of the Society for Personality and Social Psychology, Palm Springs, CA, 2006. Address correspondence to Jessica M. Nolan, Department of Psychology, University of Arkansas, Fayetteville, AR 72701; e-mail: jmn03@uark.edu. 
Normative social influence is potent and widespread. The cumulative findings from the research on normative social influence are clear-witnessing the actions of other people has a powerful effect on behavior (Asch, 1956; Berkowitz, 1972; Darley \& Latané, 1970; Deutsch \& Gerard, 1955; Milgram, Bickman, \& Berkowitz, 1969; Sherif, 1936; for a review, see Cialdini \& Goldstein, 2004). It can lead people to say things they know to be untrue (Asch, 1956), to use illicit drugs (Maxwell, 2002), or to fail to respond to an imminent threat (Latané \& Darley, 1970). In these situations, it seems clear that the direct personal experience of wit- nessing another person act can be influential in one's own actions (Terry \& Hogg, 2001; Turner, 1991).

More recent research has shown that direct observation of others is not required for normative social influence to have its effect. Instead, communicating a descriptive norm-how most people behave in a given situation-via written information can induce conformity to the communicated behavior (Parks, Sanna, \& Berel, 2001; Von Borgstede, Dahlstrand, \& Biel, 1999).

For example, Schultz (1999) found that households that received normative information describing the amount recycled by an average neighborhood family increased both the amount and frequency of their subsequent curbside recycling behaviors. Similar results were found in a hotel setting where normative messages increased towel reuse by more than 28\% (Goldstein, Cialdini, \& Griskevicius, in press). The use of written normative information has also become common practice in attempts to reduce heavy drinking among college students (e.g., Haines \& Spear, 1996; Perkins, 2003).

\section{Detecting Social Influence}

Having established the tenacity of normative social influence, researchers have now begun to question and speculate about the extent to which people are able to detect the influence of social norms on behavior (Cialdini, 2005; Schultz, Nolan, Cialdini, Goldstein, \& Griskevicius, 2007). When choosing to engage in a given behavior (e.g., Cialdini, Reno, \& Kallgren, 1990) or reporting an opinion (Griskevicius, Goldstein, Mortensen, Cialdini, \& Kenrick, 2006; Von Borgstede et al., 1999), do individuals recognize the real or imag- ined presence of others as a causal antecedent? Is con- formity to normative social influence the result of a conscious or nonconscious influence on behavior?

\section{Nonconscious Influences on Behavior}

In the past 25 years, substantial attention has been given to the study of nonconscious influences on behavior (Bargh, 2006). Much of this research has used subtle activation, or "priming," of a concept followed by subsequent observation of the participant on a behavior related to that concept (e.g., Bargh, Chen, \& Burrows, 1996; Shariff \& Norenzayan, 2007). This research has produced unexpected results, showing that subtle, imperceptible primes can produce strong and perceptible changes in behavior. In the realm of social norms and conformity, research has shown that activating the goal of going to the library, which is associated with the situational norm of being quiet, led participants to lower their voices (Aarts \& Dijksterhuis, 2003). Similarly, participants who were primed with words related to conformity (e.g., adhere, agree, comply) were subsequently more likely to conform to the opinions of confederates who gave very favorable evaluations of a boring task (Epley \& Gilovich, 1999). The observed behavior of other people may also be processed nonconsciously. For example, participants mimicked a confederate who was either rubbing their face or shaking their foot but were unaware that they had done so (Chartrand \& Bargh, 1999).

Influence is also considered nonconscious when the stimulus is perceived but is not evaluated as influential 
(Bargh, 1992, 1999; Bowers, 1984; Nisbett \& Wilson, 1977). For example, a plethora of laboratory and field studies on the bystander effect has shown that the pres- ence of other people reduces the probability that any one person will offer help (for a review, see Latané \& Nida, 1981). Although the bystander effect is well established in the social psychological literature and is known to have a reliable impact on behavior, during debriefing, individuals generally deny the impact of the presence of other people on their decision not to help (Latané \& Darley, 1970). Similarly, in Sherif's (1937) classic study on conformity during an ambiguous task, participants denied that their judgments of how much the light moved were influenced by the estimates given by other people in their group. These informal observations suggest that even in situations where the participant is likely to be aware of a causal stimulus, they may fail to identify this stimulus as the cause of their subsequent behavior. Cialdini (2005) has argued that given the ubiquity and strength of normative social influence, it is surprising how little note people take of this potent form of influence when, as observers, they decide how to interpret the causes of their own actions.

\section{Naive Psychology}

People may have been unable to discern the influence that the presence of others had on their behavior because they had an existing cultural theory that pro- vided them with a plausible alternative explanation for their behavior (e.g., "I didn't help because it's better to mind your own business”). Thus, people's naive explanations for their behavior may get in the way of detecting the true cause of behavior.

Naive psychology refers to the layperson's conception of behavior and mental processes (Heider, 1958). Nisbett and Wilson (1977) referred to these naive explanations as a priori, or implicit, causal theories. They concluded that verbal reports of behavior, more often, represented these culturally shared theories that could be generated equally well by an observer. For example, in reporting on how factors such as physical appearance and academic credentials influenced judgments of intelligence, flexibility, sympathy, and likeability, actors' estimates were highly inaccurate and no better than that of observers (Nisbett \& Bellows, 1977).

Individuals suffer from an introspection illusion when judging the cause of their own behavior (Pronin, Molouki, \& Berger, 2007). That is, individuals place greater weight on introspective thoughts and beliefs related to their decision to conform than to the behavioral evidence of their conformity. For example, if Jane is told that most students at her university support a change in the early decision policy, then she is more likely to support the change in policy herself, compared to those who are told that most students do not support the change. However, when asked why she supports the change in policy, Jane is likely to cite personal thoughts and reasoning as the most influential cause for her support.

\section{Overview}

Although many studies have demonstrated the power of social norms, few studies have looked at whether par- ticipants are able to detect the influence of social norms on their own behavior. The present research is concerned with the contention that individuals sorely underesti- mate the extent to which their actions in a situation are determined by the similar actions of others. We examine this prediction in a domain that has received substantial public attention - the behavioral dimensions of climate change. For a variety of reasons (e.g., dwindling supplies of nonrenewable energy, concern for the welfare of future generations, and a general reverence for nature), numerous organizations have urged citizens toward a pro-environmental stance and away from environmen- tally damaging activities.

In the present research, our purpose was to investigate participants' awareness of the causal relationship between descriptive social norms and their behavior. To do so, we conducted two studies. In Study 1 (a large- scale, stratified, telephone survey), we explored respon- dents’ stated reasons for engaging in energy 
conservation. Study 1 also provided an initial test of the actual factors influencing participants' conservation behavior. In Study 2 (a field experiment), we extended existing research on normative social influence by assessing participants' awareness of the extent to which different messages affected their behavior. Study 2 also provides a direct test of the accuracy of the causal explanations elicited from participants in Study 1.

\section{STUDY 1}

The goal of this first study was to conduct a preliminary investigation into the extent to which people's beliefs about what motivates them to conserve energy correspond to the factors that correlate with their self- reported intention to conserve. We wanted to know what a priori beliefs people held about why they con- serve energy and to examine the relative weight that participants would ascribe to social norms as a factor in their decisions to conserve energy at home. To address these questions, we surveyed a diverse sample of California residents regarding their energy conservation behaviors, motivations for conserving energy, and relevant normative and nonnormative beliefs.

\section{Method}

Participants. The survey data reported here were part of a larger survey of energy conservation beliefs, motivations, and actions among Californians. Data in that larger survey were collected quarterly for a 3-year period. The data reported below are from random-digit-dialing interviews with 810 participants obtained between October 2003 and January 2004, when the addition of certain survey items allowed for a test of the hypotheses of the present study.

Materials. Survey items were designed to measure self-reported efforts to conserve energy, perceived rea- sons for conservation, beliefs about the broad benefits of energy conservation, descriptive normative beliefs regarding energy conservation, and demographics.

Self-reported intention to conserve was measured by the question "How often do you try to conserve energy?” (never $=1$, sometimes $=2$, frequently $=3$, almost always $=4$ ). Along with this item, we also included a question about the perceived extent to which various factors, including the descriptive norm, motivated participants to conserve. To better understand the naive psychology of conserving energy, we selected three commonly used arguments that are employed in public appeals to con- serve energy (see Goldstein \& Cialdini, 2007): saving money, environmental protection, and social responsibility. We also included an item that asked participants about the importance of social norms in their decisions to conserve energy. The questions read, "In deciding to conserve energy, how important is it to you ... " (a) that using less energy saves money, (b) that it protects the environment, (c) that it benefits society, and (d) that a lot of other people are trying to conserve energy. Responses were made on a 4-point scale (not at all important $=1$, somewhat important $=2$, very important $=3$, extremely important $=4$ ).

In addition to measuring the reported reasons for conserving energy, we also asked about their beliefs related to energy conservation. That is, we asked about their broad beliefs regarding energy conservation, not whether these beliefs motivated them to act. This would allow us to look at the relationship between beliefs and intention and to provide an initial assessment of the accuracy of participants' naive beliefs. The questions were as follows: (a) How much do you think conserving energy will benefit society? (b) How much do you think conserving energy will protect the natural environment? (c) How much money do you think you can save by conserving energy in your home? and (d) How often do you think your neighbors try to conserve energy? Responses were on a 4-point scale ranging from 1 (not at all) to 4 (extremely). 
Descriptive normative beliefs were measured with three items: "How often do you think your neighbors try to conserve energy" (never $=1$, sometimes $=2$, frequently $=3$, almost always $=4$ ), "How often do you think residents of your city try to conserve energy?" and "How often do you think Californians try to conserve energy?” The items were averaged to create a scale score; Cronbach's alpha for the three normative belief items (neighbors, city residents, Californians) was .79 $(M=2.58, S D=.63)$. Demographic items included gender, age, ethnicity, education, income, and household size.

One potential limitation in our study is the use of single- item measures. However, single-item measures may be less problematic than is often thought. For example, previous research on job satisfaction has shown that single-item measures are often as accurate as multi-item scales (Wanous, Reichers, \& Hudy, 1997).

Procedure. Survey data were collected with the collaboration of the Social and Behavioral Research Institute (SBRI) at California State University (CSU), San Marcos. Data were collected using Computer Assisted Telephone Interviewing (CATI) software and were stratified by region of the state (Northern, Bay Area, Central, Los Angeles, Southern). The interviews lasted an average of $13 \mathrm{~min}$. The response rate was $40 \%$ and the cooperation rate was $48 \%$ (see Council of American Survey Research Organizations, 1982, for description of these measures). Surveys were conducted in either English (88\%) or Spanish (12\%).

\section{Results and Discussion}

Before analyzing the data, we examined the representativeness of the sample by comparing the age, gender, ethnicity, and income distributions of the sample with the 2000 California Census. Of the demographic data we collected, there were no substantial deviations from California census data.

Naive psychology ofenergyconservation. The survey contained a series of items about the perceived reasons for energy conservation. The items read, “In deciding to conserve energy, how important is it to you. . .” These items reflect a respondent's perceptions, or causal beliefs, about why they engaged in conservation activities. As shown in Table 1, the most highly rated reason for conserving energy was environmental protection $(M=3.41, S D=.75)$, followed by benefits to society $(M=3.17, S D=.77)$, saving money $(M=3.07, S D=.76)$, and other people are doing it $(M=$ 2.93, $S D=.83)$. A one-way, within-subjects ANOVA revealed significant differences across the four reasons for conservation, $F(3,2400)=87.17, p<.001$; all means were significantly different from each other $(p<.01)$. These results, which suggest that people are motivated to conserve energy out of a concern for the environment or future generations, is consistent with research showing that people tend to generate causal theories that are self- serving (Kunda, 1987). That is, people see themselves as conserving because it "saves the environment" or "ensures a happy future for children," but they are less likely to believe that the behavior of others would have an influence on their own conservation behaviors. Regardless of their accuracy, naive explanations of behavior can have an influence on self-reports (Malle, 1999).

As follow-up analyses to the stated reasons for conservation, we examined the relationship between conservation efforts and beliefs about saving energy: saving energy saves money, benefits future generations, protects the environment, and other people (i.e., my neighbors) are saving energy. Correlation coefficients showing the strength of the relationship between each of these beliefs and reported levels of conservation are shown in Table 1. As shown, the strongest predictor of energy conservation was the belief that other people are doing it $(r=.45, p<.01)$, despite the fact that it was rated as the least important motivating factor. The other beliefs about energy conservation were only weakly correlated with behavior: saving money $(r=.03)$, environmental protection $(r=.06)$, and benefiting future generations $(r=.23, p<.01)$. 
Normative beliefs and behavior. The primary goal of a second set of analyses was to further examine the relation- ship between descriptive normative beliefs and conservation behavior and to provide an initial test of how well people can detect normative social influence. We con- ducted a hierarchical multiple regression using descriptive normative beliefs to predict self-reported intentions to conserve energy after controlling for demographic variables and naive beliefs about conservation.

To examine the unique contribution of descriptive normative beliefs on conservation behavior, we con- ducted a three-step hierarchical multiple regression. On the first step, the demographic variables of gender, age, income, education, and language of the survey were entered. On the second step, the four reported reasons for conservation (i.e., saving money, environmental protection, social responsibility, others are doing it) were entered. Finally, on the third step, we entered the three-item descriptive normative belief scale. Because we wanted to see the unique contribution of each variable, each variable was forced into the equation; we did not use a stepwise procedure. The final regression equation was statistically significant, $F(10,640)=17.02, p<.001$. On the first step, demographic variables alone explained $8 \%$ of the variance, with age and gender making a significant contribution to the prediction of conservation efforts.

TABLE 1:Naive Explanations for Energy Conservation and Correlation Between Broad Beliefs About Energy Conservation and Self-Reported Behavior

\begin{tabular}{|l|c|c|c|c|}
\hline \multirow{2}{*}{} & \multicolumn{2}{|l|}{$\begin{array}{l}\text { Naive Explanations for } \\
\text { Energy Conservation }\end{array}$} & $\begin{array}{l}\text { Correlation Between } \\
\text { BroadBeliefs About } \\
\text { Conservation and } \\
\text { Self-Reported Behavior }\end{array}$ \\
\cline { 2 - 5 } & $\mathrm{M}$ & $\mathrm{SD}$ & $\mathrm{r}$ & $\mathrm{SE}$ \\
\hline Environmental protection & $3.41_{\mathrm{a}}$ & .75 & $.06 \mathrm{a}$ & .04 \\
\hline Benefit to society & $3.17 \mathrm{~b}$ & .77 & $.23 \mathrm{~b}$ & .04 \\
\hline Saving money & $3.07 \mathrm{c}$ & .76 & $.03 \mathrm{a}$ & .04 \\
\hline Other people are doing it & $2.93 \mathrm{~d}$ & .83 & $.45 \mathrm{c}$ & .04 \\
\hline
\end{tabular}

NOTE: Standard error was calculated using the standard error formula for $r^{\prime}(S E=\sqrt[1]{N-3}), N=$ 807. Means in the same column that do not share the same subscripts differ at $p<.05$. 
TABLE 2: $\quad$ Final Regression Weights, $t$ Values, and $p$ Values for All Predictors of Self-Reported Intention to Conserve

\begin{tabular}{|c|c|c|c|}
\hline Predictor & $\begin{array}{l}\text { Beta } \\
\text { (standardized) }\end{array}$ & t Value & $\mathbf{p}$ \\
\hline \multicolumn{4}{|l|}{ Demographics } \\
\hline Age & .21 & 5.71 & .00 \\
\hline Gender & -.01 & -0.15 & .89 \\
\hline Income & -.06 & -1.52 & .13 \\
\hline Education & .01 & 0.26 & .79 \\
\hline Language of survey & -.09 & -2.03 & .04 \\
\hline \multicolumn{4}{|c|}{ Naive explanations for conservation } \\
\hline Environmental protection & .17 & 3.56 & .00 \\
\hline Benefit to society & -.00 & -0.05 & .96 \\
\hline Saving money & .15 & 3.66 & .00 \\
\hline Other people are doing it & .04 & 1.01 & .31 \\
\hline Descriptive normative beliefs & .26 & 6.89 & .00 \\
\hline
\end{tabular}

The addition of naive explanations for conservation behavior on the second step increased the explained variance to $15 \%$, with saving money and environmental protection as significant predictors. The addition of descriptive normative beliefs to the prediction equation increased the explained variance to $21 \%$. The significant predictors in the final equation were age, with older participants reporting more conservation than younger ones; language of the survey, with English-speaking respondents conserving more than Spanish-speaking respondents; saving money; environ- mental protection; and descriptive normative beliefs. Table 2 shows the final regression weights for all of the predictor variables included in the regression analysis. By controlling for the naive explanations of conservation behavior, the degree to which descriptive normative beliefs are predictive of behavior in the final step represents an influence on behavior that is not recognized by the respondent.

Consistent with the kinds of appeals used in popular discourse, our participants reported that several factors influenced their conservation behavior, such as the desire to save money, save the environment, and benefit society in general. Of interest, they reported that their normative beliefs had the least impact on their overall conservation behavior relative to all other motivations. Yet, despite the perception that other people's behavior was least influential on their decision to conserve, beliefs of how often their neighbors tried to conserve showed a strong correlation with respondents' own reported conservation efforts. 


\section{STUDY 2}

Our initial study allowed us to acquire a rich set of data. Unlike in similar research of this nature, our large and wide-ranging sample consisted of people who differed on many important demographic dimensions, including socioeconomic status, age, ethnicity, and gender. Not only did this representative sample enable us to examine the impact of social norms across these different demographic variables, it also gave us more confidence in the reliability and generalizability of our findings. Of course, the correlational nature of the study did not allow us to establish causal relationships.

To further examine the perceived influence of normative information, we conducted a second study using an experimental design. This time, we wanted to use normative information to change behavior and then to examine perceptions of the degree to which the normative information was motivational. Once again, our participants consisted of a sample of California residents, except that this time we provided household members with a specific appeal urging them to conserve energy in the home. Three of the appeals used a nonnormative message based on one of the three reasons for saving energy that our Study 1 participants identified as most influential: to protect the environment, to benefit society, or to save money. A separate appeal simply communicated a descriptive norm indicating that the majority of the recipient's neighbors conserved energy - the same type of normative information that respondents in our first study considered the least motivational but showed the strongest relationship with their reported efforts to conserve. The effects of these four appeals were compared to a control condition that included an information-only appeal.

Besides manipulating the type of information that participants received, Study 2 improved on our initial study in another important way: The dependent variable was participants' actual energy use in the home as indicated by their electricity meter readings before and after the intervention. Having access to participants' meters not only reduced the possible effects of self- presentation and memory bias but also provided a direct measure of the behavior of interest.

With regard to participants' actual energy consumption, we hypothesized that the descriptive norm condition would be superior to all of the other conditions at motivating energy conservation. That is, households in the descriptive norm condition would show the lowest level of energy consumption following the intervention. We had a separate set of predictions related to participants' awareness of the influence of the messages on their energy conservation behavior. Although we expected the descriptive norm condition to be most efficacious, we also expected, based on the results of Study 1, that participants would rate the normative message as least influential. We also predicted that consistent with the naive explanations provided in Study 1, participants would rate the social responsibility and environmental messages as most motivating but that this verbal report of motivation would not correspond to actual conservation.

In summary, we aimed to accomplish three goals in Study 2: extend the research on normative social influence, assess participants' ability to detect the influence of normative information, and test the accuracy of naive psychology-based explanations of energy conservation.

\section{Methods}

Participants. Our field study began with a starting sample of 981 households in the middle-class neighbor- hoods of San Marcos, California. ${ }^{1}$ Of those 981 house- holds, 509 participated in a postintervention interview (52\%). Included in the present study are 371 house- holds from the sample of interviewed households (73\%) that reported seeing and reading the doorhangers that were distributed during the intervention. There are several possibilities for why people did not report seeing the doorhangers. First, respondents may have seen the doorhangers but forgot about them at the time of the interview. Second, the person who responded to our interview may not have been the same person within the household who discovered the doorhangers. A chi- square analysis showed that there were no significant differences in how many people saw and read the doorhangers across the five conditions, 
$\mathrm{X}^{2}(4, N=509)=6.63$, $n s$. The average respondent was 46 years old, had 8.6 years of tenure at the address, and reported an average household size of 3.2 people.

Materials and procedure. Households were randomly assigned to receive one of five experimental messages: descriptive norm, self-interest, environment, social responsibility, or information-only control.

Intervention. Before the study began, households received a mailed postcard notifying them that a study was being conducted in their neighborhood. The postcard provided contact information for our university research team and offered residents the opportunity to withdraw from the study (none did so). Five days after the postcards were mailed, trained research assistants began delivering persuasive messages to each household promoting energy conservation. The messages were printed on doorhangers and contained a message promoting one energy conservation behavior along with a graphic icon illustrating the behavior. All of the doorhangers included the local university logo and contact information. The doorhangers were printed on both sides, with English on one side and a Spanish translation on the reverse. A total of four different energy conservation behaviors were promoted during this study: taking shorter showers, turning off unnecessary lights, turning off the air conditioning at night, and using fans instead of air conditioning. These behaviors were selected through a review of publications generated by the local utility: San Diego Gas and Electric (SDG\&E). The behaviors were further tested through the phone survey described in Study 1. Twenty messages, one for each of the four behaviors, were created for each of the five conditions. Doorhangers in the information-only condition stated only that participants could save energy by adopting the behavior being promoted. In the descriptive norm, self-interest, environment, and social responsibility conditions, the doorhangers also contained motivational infor- mation about why the household should adopt the energy-conserving behavior (e.g., 99\% of people in your community reported turning off unnecessary lights to save energy) and a graphic that symbolized the condition (e.g., a globe for the environment condition). Samples of the headings and key information from each type of doorhanger are included in the appendix.

Of importance, the normative information presented on the doorhangers was factual. Using the survey data obtained as part of our larger statewide survey, we were able to identify a small number of completed surveys from the local region. These surveys served as the basis for our normative messages and, depending on the behavior, these percentages ranged from $77 \%$ to $99 \%$. Following the final distribution of doorhangers, all households received a postcard notifying them that student researchers would be conducting interviews in their neighborhood.

Door-to-door interviews. Following the final distribution of the doorhangers, trained interviewers, blind to condition, contacted all households included in the study to conduct interviews. Interviewers, working in teams of two, contacted households in person to administer the interview. After confirming that the respondent was a resident at that address, the interviewer obtained verbal consent and then proceeded with the interview. The interview began by asking respondents if they "saw and read one or more yellow doorhangers with information about energy conservation in the last month.” As mentioned previously, only those respondents who reported seeing and reading the doorhanger are included in the present analysis.

The remainder of the interview questions assessed the extent to which respondents perceived that the doorhangers had motivated them to conserve energy. Respondents' estimation of the influence of the doorhangers on their energy conservation behavior was measured with a single item that asked "How much did the information on these doorhangers motivate you to conserve energy?” If people rely on their a priori or naive beliefs about energy conservation when answering this question, then they should report that the social responsibility doorhanger was most effective, regardless of its actual effect. If, on the other hand, people are consciously processing the information, comparing their behavior before and after delivery of the doorhangers, then their estimates of how motivated they were should correspond to estimates of actual 
energy con- servation for each condition.

At the end of the interview, respondents were offered a free compact fluorescent light bulb and were asked to sign an authorization form granting permission to access their household energy bills from the local utility company. If no contact was made after three attempts, a mail survey with a cover letter describing the experiment was left in a self-addressed, stamped envelope at the respondent's home along with a light bulb.

Meter readings. In addition to collecting self-report data on energy conservation during the interviews and requesting access to household energy bills, the researchers read the electricity meters for households with accessible meters. Electricity meters were recorded four times during the study. The first meter reading was taken the week prior to the intervention, the second meter reading was taken on the same day that the first doorhanger was distributed, the third meter reading was taken the same day the fourth doorhanger was distributed, and the fourth meter reading was taken 1 month following the delivery of the last doorhanger. By comparing each reading to a subsequent one, we were able to calculate an average daily kilowatt use figure for the baseline, shorter-term (1 month from baseline), and longer-term (2 months from baseline) periods. In Study 1, we learned that naive beliefs about energy conservation supported causal explanations that appealed to concern for future generations, environmental protection, and saving money. Assessment of the actual energy consumption of households in these different conditions provided a direct test of the accuracy of peoples' naive causal explanations, allowing us to determine whether it was true, as people reported, that an appeal to social responsibility or environmental protection would be most effective at promoting energy conservation.

\section{Results and Discussion}

Detecting normative social influence. Participants were asked "How much did the information on these doorhangers motivate you to conserve energy?” with responses ranging from 1 (not at all) to 4 (extremely). Participants in the descriptive norm condition reported that the messages were the least motivational $(M=1.76, S E=.10)$. Pairwise comparisons showed that these scores were significantly lower than for participants in the environmental condition $(M=2.07, S E=.08, p<.05)$ and social responsibility condition $(M=1.99, S E=.09, p<.08)$ but not significantly different from the self-interest condition $(M=1.86, S E=.08)$ or the information-only condition $(M=1.94, S E=.11)$. This pattern is similar to that found in the survey data reported in Study 1, wherein environmental reasons and social responsibility were identified as the two reasons that people believed were most influential to conserve energy.

Meter readings. To assess the reliability of our meter readings, two research assistants were assigned to read the same meter on multiple occasions (4\% of all readings). The independent readings correlated at $r=.999$. In addition, our measure of electricity use correlated with data provided by the local utility company at $r=.964$ during the short term (June) and at $r=.992$ long term (July). The correlations between our measures and SDG\&E were for those households that granted permission to access their bill $(N=187)$. This high correlation with data provided by the utility company supports the validity of our meter readings measure. Meter data were converted to kilowatt hours used per day. Use during the short term correlated at $r=.61$ with long-term use. 
TABLE 3: Short-Term and Long-Term Energy Consumption Adjusted for Baseline Energy Consumption

\begin{tabular}{|l|l|l|l|l|}
\hline \multicolumn{2}{|l|}{$\begin{array}{l}\text { Energy Consumption in Average Daily Kilowatt Hours } \\
(\mathrm{kWh})\end{array}$} & \multicolumn{2}{l|}{ Long Term } \\
\hline & Short Term & SE & M & SE \\
\hline Condition & M & .39 & 16.89 & .81 \\
\hline Environmental protection & 16.89 & .41 & 17.52 & .85 \\
\hline Social responsibility & 17.52 & .40 & 17.45 & .82 \\
\hline Self-interest & 17.45 & .44 & 16.10 & .93 \\
\hline Social norm & 16.10 & .45 & 17.36 & .94 \\
\hline Information control & 17.36 & & \\
\hline
\end{tabular}

Our second step was to establish that the stimulus of interest, in this case the normative information, had an effect on behavior. Of the 371 households that we inter- viewed, 271 produced usable meter data. $^{2}$ A 5 (condition) X 2 (meter readings available: yes or no) ANOVA showed that there were no differences between those included in the meter reading analysis and those who were not on the measure of how much the doorhangers motivated them to conserve energy, $F(1,369)=.62$, ns. The meter data provided the dependent variable in a series of analyses designed to test the impact of our persuasive messages. To account for differences in baseline electricity use across groups, we conducted a one-way ANCOVA with baseline use as a covariate and the short-term meter data as the dependent variable. The baseline covariate was significant, $F(1,265)=1025.33, p<.001$. In support of one of our major hypotheses, a planned contrast revealed that participants in the descriptive norm condition $\left(M_{a d j}\right.$ $=12.97, S E=.44, N=46)$ used significantly less energy short term than did participants in the combined other conditions $\left(M_{\text {adj }}=14.17, S E=.20\right), F(1,268)=5.99, p<.05$. Table 3 provides the means and standard errors for each of the five conditions, adjusted for baseline energy consumption.

The pattern of means for long-term use was similar, with the descriptive group consuming the least amount of electricity, after controlling for baseline use. Again, we conducted a one-way ANCOVA with baseline energy consumption as the covariate and long-term energy consumption as the dependent variable. The baseline covariate was significant, $F(1,264)=309.16, p<.001$. As shown in Table 3 , the pattern of means for long-term energy consumption was similar to short- term use, with the descriptive norm condition $\left(M_{a d j}=\right.$ consuming the least amount of energy compared to the other conditions.

However, the planned contrast of descriptive norm versus the combined mean of the other conditions was not significant, $F(1,268)=1.42, p=.24$. The nonsignificant contrast for the long-term energy data suggests that the impact of the descriptive norm message had begun to erode in the 1 month following the intervention. The increase in energy consumption from short term to long term reflects seasonal changes in the weather, independent of our intervention. Overall, these results are inconsistent with the naive psychology-based explanations of conservation endorsed in Study 1.

In summary, despite the private nature of conserving energy in the home, normative social influence had a direct impact on residents' conservation behavior. Meter readings showed that a descriptive normative message - a message merely containing information about the conservation behavior of the majority of one's neighbors - spurred people to conserve more energy than did the control message or any of the three other messages that contained appeals that are traditionally accorded motivational power. That is, the three messages using arguments based on motivations that were rated as being the most influential in Study 1 fared worse at spurring conservation behavior than just providing people with normative information about their neighbors' conservation efforts. Furthermore, the experimental nature of Study 2 con- firmed that the positive relationship between descriptive norms and behavior in Study 1 was 
not simply due to a false consensus effect. Of interest, although the normative message was most effective at changing behavior, residents did not detect the influence of these messages, rating them as least motivating.

\section{GENERAL DISCUSSION}

In conclusion, we found that naive psychology-based beliefs about energy conservation were inaccurate predictors of actual energy conservation. Implicit theories of energy conservation-related motives were plainly wrong. Despite the fact that participants believed that the behavior of their neighbors - the descriptive norm - had the least impact on their own energy conservation, results showed that the descriptive norm actually had the strongest effect on participants' energy conservation behaviors. That is, normative information spurred people to conserve more energy than any of the standard appeals that are often used to stimulate energy conservation, such as protecting the environment, being socially responsible, or even saving money. Descriptive norms had a powerful but underdetected effect on an important social behavior: energy conservation.

A similar pattern of results can be found in research on the indirect effects of minority influence. In studies examining the extent to which minority group members can exert influence on group decisions, people often deny the influence of minority sources on their attitudes. Yet, the results show clear evidence that group members are influenced by minority sources on both private and delayed measures of attitude change (Aebischer, Hewstone, \& Henderson, 1984; Alvaro \& Crano, 1996; Crano, 2001; Maass \& Clark, 1983; for a review, see Maass \& Clark, 1984) and on attitudes that are related to the focal issue of the persuasive message (e.g., De Dreu, De Vries, Gordijn, \& Schuurman, 1999). Taken together, it seems that both informational and normative social influence are underdetected.

In our study, had the participants been aware of the influence of the normative information on their energy conservation behavior during the intervention, we may not have seen such a dramatic decrease in consumption. Research on mental contamination suggests that when people are made aware that unwanted agents may be influencing their judgments, they often will try to correct for any biasing effects (for a review, see Wilson \& Brekke, 1994). Consider the impact of being informed about pluralistic ignorance. As social psychologists, our knowledge of the biasing effects of the presence of others in emergency situations allows us to act when others might not. We know that the lack of action on the part of others cannot be taken as proof that everything is fine. Future research can examine whether and how forewarning influences the effectiveness of normative social influence.

Another interesting result from these studies is what did not work. Whereas environmental reasons and social responsibility were rated as strong reasons for conserving energy in our survey, neither approach succeeded in reducing energy conservation in our field study. On the surface, this might appear surprising. Yet, the results are consistent with a growing body of research on environmental education and proenvironmental behavior - appealing to people to do the right thing, or to protect the environment, rarely succeeds in increasing levels of pro-environmental behavior (see Schultz, 2002, for a discussion).

But this does not mean that environmental protection or social responsibility cannot motivate proenvironmental behavior, only that messages promoting an increase in conservation fail to produce behavior change. It seems plausible that people are already engaging in conservation efforts for these reasons and appealing to these motivational bases merely preaches to the choir. What is needed is an alternative motivational basis that appeals to a different portion of the population or an alternative behavior that has not yet been linked with environmental or social responsibility (Schultz \& Zelezny, 2003). By going beyond environ- mental protection and social responsibility, normative messages reach a new population of individuals who might not otherwise have a reason to conserve.

There is a potential alternative explanation for the results obtained in Study 2 that warrants discussion. It is possible that the difference between the descriptive norm group and the other conditions is the result of a difference in how the messages were processed. Specifically, including the 
term "your community" in the descriptive norm message may have made this message more personally relevant, and therefore more likely to be centrally processed, compared to the messages in the other conditions (Petty \& Cacioppo, 1986). Although we cannot rule out this possibility entirely, it seems unlikely. First, research on majority influence has shown that presenting consensus information reduces the degree to which messages are processed systematically (Erb, Bohner, Schmälzle, \& Rank, 1998). Second, if the messages appeared more personally relevant, then we might also expect to see that more people attended to the descriptive norm messages, compared to the other conditions, which we did not. Third, results similar to ours were found in a comparable study on recycling that used common language across conditions (Schultz, 1999). Future research is needed to better understand the basic question of how normative messages are processed in a real-world setting as well as the specific question of whether part of the effectiveness of normative messages can be attributed to an increase in personal relevance.

In addition to their important theoretical contributions, these results have other practical implications as well. It is common practice for program designers to conduct focus groups in the process of designing their behavior change programs. The problem is that asking people what they think would influence them may not provide good data on which to base solutions. In fact, our results suggest that people hold incorrect beliefs about what motivates them to conserve and may not be able to predict which strategies will be the most effective. Taken together, the results from the current studies show that normative information is a powerful but underdetected form of social influence. As in previous studies (e.g., Schultz, 1999), we showed that normative information was a highly effective way to motivate a change in behavior. Also in line with previous research on nonconscious influences on behavior (e.g., Bowers, 1984; Nisbett \& Wilson, 1977), we found that people were unable to identify the true cause of their behavior. Although participants in the environment and social responsibility conditions were most likely to say that they had been influenced by the persuasive message they received, their energy consumption did not differ from the control group, whereas the descriptive norm condition did differ. These results suggest that people relied on their a priori theories of what should motivate some- one to conserve energy. In conclusion, although people may not believe that the behavior of others should motivate them to conserve energy, their behavior was powerfully influenced by it nonetheless.

\section{APPENDIX SAMPLE INTERVENTION MESSAGES USED IN STUDY 2}

Descriptive Norm: Join Your Neighbors in Conserving Energy. Summer is here and most people in your community are finding ways to conserve energy at home. How are San Marcos residents like you conserving this summer? By using fans instead of air conditioning! Why? In a recent survey of households in your community, researchers at Cal State San Marcos found that 77\% of San Marcos residents often use fans instead of air con- ditioning to keep cool in the summer. Using fans instead of air conditioning-Your Community's Popular Choice!

Self-Interest: Save Money by Conserving Energy. Summer is here and the time is right for saving money on your home energy bill. How can you save money this summer? By using fans instead of air conditioning! Why? According to researchers at Cal State San Marcos, you could save up to \$54 per month by using fans instead of air conditioning to keep cool in the summer.

Environmental Protection: Protect the Environment by Conserving Energy. Summer is here and the time is right for reducing greenhouse gases. How can you protect the environ- ment this summer? By using fans instead of air conditioning! Why? According to researchers at Cal State San Marcos, you can prevent the release of up to 262 lbs of greenhouse gases per month by using fans instead of air conditioning to keep cool this summer! Using fans instead of air conditioning-The Environmental Choice. 
Social Responsibility: Do Your Part to Conserve Energy for Future Generations. Summer is here and we need to work together to conserve energy. How can you conserve energy for future generations? By using fans instead of air conditioning! Why? According to researchers at Cal State San Marcos, you can reduce your monthly demand for electricity by $29 \%$ using fans instead of air conditioning to keep cool this summer! Using fans instead of air conditioning-The Socially Responsible Choice.

Information Only: Energy Conservation. Summer is here and the time is right to conserve energy. How can you conserve energy this summer? By using fans instead of air conditioning!

\section{NOTES}

1. Households were selected using 1999 and 2000 census data to represent high, medium, and low ethnic diversity areas with a median household income ranging from $\$ 50,000$ to $\$ 72,000$. High diversity was defined as an area that was less than $50 \%$ White, medium diver- sity was defined as an area that was between $50.1 \%$ to $74.9 \%$ White, and low diversity was defined as an area where more than $75 \%$ of the population was White.

2. Meter readings were only taken from households that had a publicly visible electricity meter. Electricity meters that were not visi- ble upon natural egress to the home, or that could not be accessed because of the presence of a gate or a dog, were not read.

\section{REFERENCES}

Aarts, H., \& Dijksterhuis, A. (2003). The silence of the library: Environment, situational norms, and social behavior. Journal of Personality and Social Psychology, 84, 18-28.

Aebischer, V., Hewstone, M., \& Henderson, M. (1984). Minority influence and musical preference: Innovation by conversion not coercion. European Journal of Social Psychology, 14, 23-33.

Alvaro, E. M., \& Crano, W. D. (1996). Cognitive responses to minor- ity- or majority-based communications: Factors that underlie minor- ity influence. British Journal of Social Psychology, 35, 105-121.

Asch, S. E. (1956). Studies of independence and conformity: A minor- ity of one against a unanimous majority. Psychological Monographs, 70, 1-70.

Bargh, J. A. (1992). Does subliminality matter to social psychology? Awareness of the stimulus versus awareness of its influence. In

R. F. Bornstein \& T. S. Pittman (Eds.), Perception without aware- ness: Cognitive, clinical, and social perspectives (pp. 236-255). New York: Guilford.

Bargh, J. A. (1999, January 29). The most powerful manipulative messages are hiding in plain sight. Chronicle of Higher Education, p. B6.

Bargh, J. A. (2006). Agenda 2006: What have we been priming all these years? On the development, mechanisms, and ecology of non- conscious social behavior. European Journal of Social Psychology, 36, 147-168.

Bargh, J. A., Chen, M., \& Burrows, L. (1996). Automaticity of social behavior: Direct effects of trait construct and stereotype priming on action. Journal of Personality and Social Psychology, 71, 230-244.

Berkowitz, L. (1972). Social norms, feelings, and other factors affect- ing helping and altruism. Advances in Experimental Social Psychology, 6, 63-108.

Bowers, K. S. (1984). On being unconsciously influences and informed. In K. S. Bowers \& D. Meichenbaum (Eds.), The uncon- scious reconsidered (pp. 227-273). New York: John Wiley. Chartrand, T. L., \& Bargh, J. A. (1999). The chameleon effect: The perception-behavior link and social interaction. Journal of Personality and Social Psychology, 76, 893-910. 
Cialdini, R. B. (2005). Basic social influence is underestimated.

Psychological Inquiry, 16, 158-161.

Cialdini, R. B., \& Goldstein, N. J. (2004). Social influence: Compliance and conformity. Annual Review of Psychology, 55, 591-621.

Cialdini, R. B., Reno, R. R., \& Kallgren, C. A. (1990). A focus theory of normative conduct: Recycling the concept of norms to reduce littering in public places. Journal of Personality and Social Psychology, 58, 1015-1026.

Council of American Survey Research Organizations. (1982). On the definition of response rates: A special report of the CASRO taskforce on completion rates. Retrieved June 5, 2004, from Council of American Survey Research Organizations (http://www.casro.org/resprates.cfm)

Crano, W. D. (2001). Social influence, social identity, and ingroup leniency. In C.K.W. de Dreu \& N. K. de Vries (Eds.), Group consen- sus and minority influence (pp. 122-143). Oxford, UK: Blackwell.

Darley, J. M., \& Latané, B. (1970). Norms and normative behavior: Field studies of social interdependence. In J. Macaulay \& L. Berkowitz (Eds.), Altruism and helping behavior (pp. 83-102). New York: Academic Press.

De Dreu, C.K.W., De Vries, N. K., Gordijn, E. H., \& Schuurman, M. s. (1999). Convergent and divergent processing of majority and minority arguments: Effects on focal and related attitudes. European Journal of Social Psychology, 29, 329-348.

Deutsch, M., \& Gerard, H. B. (1955). A study of normative and infor- mational social influences upon individual judgment. Journal of Abnormal and Social Psychology, 51, 629-636.

Epley, N., \& Gilovich, T. (1999). Just going along: Nonconscious priming and conformity to social pressure. Journal of Experimental Social Psychology, 35, 578-589.

Erb, H.-P., Bohner, G., Schmälzle, K., \& Rank, S. (1998). Beyond con- flict and discrepancy: Cognitive bias in minority and majority influ- ence. Personality and Social Psychology Bulletin, 24, 620-633.

Goldstein, N. J., \& Cialdini, R. B. (2007). Using social norms as a lever of social influence. In A. Pratkanis (Ed.), The science of social influ- ence: Advances and future progress. Philadelphia:

Psychology Press. Goldstein, N. J., Cialdini, R. B., \& Griskevicius, V. (in press). A room with a viewpoint: Using social norms to motivate environmental conservation in hotels. Journal of Consumer Research.

Griskevicius, V., Goldstein, N. J., Mortensen, C. R., Cialdini, R. B., \& Kenrick, D. T. (2006). Going along versus going alone: When fundamental motives facilitate strategic (non)conformity. Journal of Personality and Social Psychology, 91, 281-294.

Haines, M., \& Spear, S. (1996). Changing the perception of the norm: A strategy to decrease binge drinking among college students. Journal of American College Health, 45, 134-140.

Heider, F. (1958). The psychology of interpersonal relations. New York: John Wiley.

Kunda, Z. (1987). Motivated inference: Self-serving generation and evaluation of causal theories. Journal of Personality and Social Psychology, 53, 636-647.

Latané, B., \& Darley, J. M. (1970). The unresponsive bystander: Why doesn't he help? New York: Appleton-Century-Crofts.

Latané, B., \& Nida, S. (1981). Ten years of research on group size and helping. Psychological Bulletin, 89, 308-324.

Maass, A., \& Clark, R. D. (1983). Internalization versus compliance: Differential processes underlying minority influence and confor- mity. European Journal of Social Psychology, 13, 197-215.

Maass, A., \& Clark, R. D. (1984). Hidden impacts of minorities: Fifteen years of minority influences research. Psychological Bulletin, 95, 428-450.

Malle, B. F. (1999). How people explain behavior: A new theoretical framework. Personality and Social Psychology Review, 3, 23-48.

Maxwell, K. (2002). Friends: The role of peer influence across adolescent risk behaviors. Journal of 
Youth and Adolescence, 31, 267-277.

Milgram, S., Bickman, L., \& Berkowitz, L. (1969). Note on the draw- ing power of crowds of different size. Journal of Personality and Social Psychology, 13, 79-82.

Nisbett, R. E., \& Bellows, N. (1977). Verbal reports about causal influences on social judgments: Private access versus public theo- ries. Journal of Personality and Social Psychology, 35, 613624.

Nisbett, R. E., \& Wilson, T. D. (1977). The halo effect: Evidence for unconscious alteration of judgments. Journal of Personality and Social Psychology, 35, 250-256.

Parks, C. D., Sanna, L. J., \& Berel, S. R. (2001). Actions of similar others as inducements to cooperate in social dilemmas. Personality and Social Psychology Bulletin, 27, 345-354.

Perkins, H. W. (2003). The emergence and evolution of the social norms approach to substance abuse prevention. In H. W. Perkins (Ed.), The social norms approach to preventing school and college age substance abuse: A handbook for educators, counselors, and clinicians (pp. 3-18). San Francisco: Jossey-Bass.

Petty, R. E., \& Cacioppo, J. T. (1986). Communication and persua- sion: Central and peripheral routes to attitude change. New York: Springer-Verlag.

Pronin, E., Molouki, S., \& Berger, J. (2007). Alone in a crowd of sheep: Asymmetric perceptions of conformity and their roots in an intro- spection illusion. Journal of Personality and Social Psychology, 92, 585-595.

Schultz, P. W. (1999). Changing behavior with normative feedback interventions: A field experiment on curbside recycling. Basic and Applied Social Psychology, 21, 25-36.

Schultz, P. W. (2002). Knowledge, information, and household recy- cling: Examining the knowledge-deficit model of behavior change. In T. Dietz \& P. Stern (Eds.), Education, information, and volun- tary measures in environmental protection (pp. 67-82). Washington, DC: National Academy of Sciences.

Schultz, P. W., Nolan, J. M., Cialdini, R. B., Goldstein, N. J., \& Griskevicius, V. (2007). The constructive, destructive, and reconstructive power of social norms. Psychological Science, 18, 429-433.

Schultz, P. W., \& Zelezny, L. (2003). Reframing environmental mes- sages to be congruent with American values. Human Ecology Review, 10, 126-136.

Shariff, A. F., \& Norenzayan, A. (2007). God is watching you: Priming God concepts increases prosocial behavior in an anony- mous economic game. Psychological Science, 18, 803-809.

Sherif, M. (1936). The psychology of social norms. New York: Harper.

Sherif, M. (1937). An experimental approach to the study of attitudes.

Sociometry, 1, 90-98.

Terry, D. J., \& Hogg, M. A. (2001). Attitudes, behavior, and social context: The role of norms and group membership in social influ- ence processes. In J. P. Forgas \& K. D. Williams (Eds.), Social influence: Direct and indirect processes (pp. 253-270). Philadelphia: Psychology Press.

Turner, J. C. (1991). Social influence. Pacific Grove, CA: Brooks/ Cole.

Von Borgstede, B., Dahlstrand, U., \& Biel, A. (1999). From ought to is: Moral norms in largescale social dilemmas. Goteborg Psychological Reports, 29, 1-19.

Wanous, J. P., Reichers, A. E., \& Hudy, M. J. (1997). Overall job sat- isfaction: How good are single-item measures? Journal of Applied Psychology, 82, 247-252.

Wilson, T. D., \& Brekke, N. (1994). Mental contamination and mental correction: Unwanted influences on judgments and evaluations. Journal of Personality and Social Psychology, 116, 117-142.

Received June 18, 2007

Revision accepted December 12, 2007 